This item was submitted to Loughborough's Research Repository by the author.

Items in Figshare are protected by copyright, with all rights reserved, unless otherwise indicated.

\title{
A cloud-based supply chain management system: effects on supply chain responsiveness
}

PLEASE CITE THE PUBLISHED VERSION

https://doi.org/10.1108/JEIM-05-2018-0106

\section{PUBLISHER}

(C) Emerald Publishing Limited

\section{VERSION}

AM (Accepted Manuscript)

\section{PUBLISHER STATEMENT}

This work is made available according to the conditions of the Creative Commons Attribution-NonCommercialNoDerivatives 4.0 International (CC BY-NC-ND 4.0) licence. Full details of this licence are available at: https://creativecommons.org/licenses/by-nc-nd/4.0/

\section{LICENCE}

CC BY-NC-ND 4.0

\section{REPOSITORY RECORD}

Giannakis, Mihalis, Konstantina Spanaki, and Rameshwar Dubey. 2019. "A Cloud-based Supply Chain Management System: Effects on Supply Chain Responsiveness". figshare. https://hdl.handle.net/2134/37567. 


\title{
A Cloud-based Supply Chain Management System: Effects on Supply Chain Responsiveness
}

\begin{abstract}
Purpose: Despite the ongoing calls for the incorporation of the cloud utility model, the effect of the cloud on elements of supply chain performance is still an evolving area of research. In this paper, we develop the architecture of a cloud-based supply chain management (C-SCM) ecosystem and explore how it enhances supply chain responsiveness.

Design/methodology/approach: First, we discuss the potential benefits that cloud computing can yield compared to existing mature SCM information systems and solutions through a comprehensive literature review. We conceptualize SCR in terms of the level of visibility in the supply chain, supply chain flexibility, and rapid detection and reaction to changes and then we build the detailed architecture of a cloud based SCM system. The proposed ecosystem introduces a view of SCM and the associated practices when transferred to cloud environments. The potential to enhance SCR through the cloud is explored with scenarios on a case of supply chain operations in fashion retail industry.

Findings: Our findings show that the proposed system can enhance all three dimensions of SCR. Implications for supply chain practice and how companies can migrate to a cloud supply chain are drawn.

Originality/Value: Given that the development, creation, and delivery of goods and services is increasingly becoming a joint effort of several parties in a supply chain, we contribute to existing literature, by introducing a comprehensive cloud-based SCM system and show how companies can enhance their supply chain responsiveness.
\end{abstract}

Keywords: Supply Chain Responsiveness; Cloud-based approach; Case Study

\section{Introduction}

The production and delivery of products or services in a timely fashion and at a minimum total cost is one the critical objectives for many companies (Christopher, 2016). The adoption of lean management practices strategies can yield positive outcomes, but the global supply chains of today are not sufficiently responsive to satisfy the requirements for short lead times needed by lean strategies (Reichhart \& Holweg, 2007). With the substantial advances in Information Technology (IT) and digital communication platforms over the past decade, there is a growing awareness that supply chain performance could be improved with the successful adoption of such technologies (Qrunfleh and Tarafdar, 2014; Hsu et al., 2014; Dwivedi and Mustafee, 2010).

The commercialisation of cloud computing may provide solutions towards these challenges. Cloud systems turn computing resources (e.g. networks, servers, storage, applications) into a general utility that can be leased and released by users through the internet in an on-demand manner (Wang, 2012; Mezgár, and Rauschecker, 2014). The shared pool of IT resources are virtualised, allowing for dynamic reconfiguration, according to various degrees and volumes of user requirements 
(Durowoju et al., 2011). In this way they can serve a wide range of geographically dispersed users, lead to lower costs of ownership and maximise scalability and rapid deployment (Cegielski et al., 2012).

Academic studies recognise the potential of cloud computing and suggest their adoption to improve business performance. Marston et al. (2011) and Garrison et al. (2015) provide a comprehensive analysis of the business benefits of cloud computing and several recommendations for policy makers to facilitate the technology, Durowoju et al. (2011) investigate how cloud computing system can enhance security and scalability of operations and Yang et al. (2015) show how cloud based systems can enhance performance of complex service operations in healthcare. Despite the ongoing calls for the incorporation of cloud systems, little research has been undertaken to explore the effect of cloud systems on elements of supply chain performance (Bayramusta and Nasir, 2016; DeGroote and Marx, 2013). Given that the development, creation and delivery of goods and services is increasingly becoming a joint effort of several parties in a supply chain, we develop the architecture of a cloud based SCM system (CSCM) and explore how its utilisation can enhance supply chain responsiveness (SCR).

The remainder of the paper is structured as follows. In section 2, we briefly present the fundamental principles and capabilities of cloud technology and discuss the implications that its adoption can have on supply chain responsiveness (SCR). We conceptualise SCR in terms of the level of visibility in the supply chain, supply chain flexibility, and rapid detection and reaction to changes. In this section we also provide an overview of the growing literature on cloud-based approaches to supply chain phenomena and draw the main differentiators of C-SCM concerning conventional supply chain information systems. In section 3 we present the architecture of the proposed C-SCM system with the use of mature modules, to ensure its compatibility with existing technologies. We provide a detailed description of each module. In section 4 we explore the utility of the proposed system with two case studies and consider the effects on SCR. The paper concludes with a discussion of the contribution and limitations of the study and potential extension of the research.

\section{Literature Review}

Over the past decade, the long-held dream of computing as a utility of Ambrust et al (2010) and Sharif (2010), and its disruptive potential to transform a large part of the IT industry (Buyya et al., 2008; Fox, 2009; Yeo et al., 2009; El Kadiri et al., 2016), has attracted high interest by enterprises. The cloud disruptive business model (Kiss et al., 2015) of making software as a service and forming the way IT hardware is designed and purchased; has increased the potentialities to reshape the way enterprises acquire and manage their computing requirements (El-Gazzar, 2014; Alshamaila et al., 2013; Armbrust et al., 2010). In line with the shared services, cloud computing is considered an innovative model for IT sourcing that generates value for the adopting enterprises (Schneider and Sunyaev, 2016). Garisson et al. (2012; 2015) referring to cloud highlight the fact that productivity can be increased as the enterprises are able to focus on their core business activities; additional benefits could be the scalability, flexibility, agility, and simplicity offered to the adopting enterprises (Garrison et al., 2012; Venters and Whitley, 2012).

Cloud computing has been given numerous definitions (Schneider and Sunyaev, 2016; El-Gazzar, 2014; Alshamaila et al., 2013; Marston et al., 2011). However, the widely known definition of cloud computing is the one given by the National Institute of Standards and Technology (NIST). The NIST defines cloud computing as "a model for enabling convenient, on-demand network 
access to a shared pool of configurable computing resources (e.g., networks, servers, storage, applications, and services) that can be rapidly provisioned and released with minimal management effort or service provider interaction"(Mell and Grance, 2011).

NIST recognises two primary actors in the cloud context: a) the Cloud Service Provider and b) the Cloud Service Consumer, there is also the Cloud Service Broker involved in a few cases (Hogan et al., 2011). Cloud service providers offer various service models depending on the enterprise's requirements, whereas the basic service models are providing three types of services (Mell and Grance, 2011; Senyo et al., 2018) infrastructure, platform, and software services in a pay-as-yougo manner via the internet (Mahmood and Hill, 2011). Each layer is encapsulated as a service to respond to the layer above (Dhar, 2012; Zhang et al., 2010).

- Software as a Service (SaaS) offers the capability of providing hosted applications over the internet in an on-demand manner (Mahmood and Hill, 2011). With SaaS, users do not need to install applications or services into their own computers but directly them online.

- Platform as a Service (PaaS) offers the capability of the consumer to deploy onto the cloud infrastructure consumer-created or acquired applications created using programming languages, libraries, services, and tools supported by the provider (Hogan et al., 2011). This provides clients or third parties with designing, developing and deploying their own applications (Mahmood and Hill, 2011). Instead of end users, IT staff and developers in third parties are the typical consumers of PaaS services (Baun, 2011).

- Infrastructure as a Service (IaaS) offers the capability of provisioning computing services in the form of storage, processing capability, network connectivity, virtual machines and other relevant services where the consumer is able to deploy infrastructure and run applications (Zhang et al., 2010).

One of the challenges for the cloud infrastructure as most of the novel technological advancments is around their adoption (Williams et al, 2015, Dwivedi and Mustafee, 2010). The cloud adoption literature (Alshamaila et al., 2013; Garrison et al., 2012; Armbrust et al., 2010) reports that at the enterprise level, cloud adoption processes vary depending on the layer (SaaS, PaaS, IaaS), the cloud deployment models and the characteristics of the specific firm (size, industry, etc.). In spite of its appealing benefits for enterprises, cloud computing raises serious technical, economic, ethical, legal, and managerial issues (Sultan, 2011; 2013; 2014; Walterbusch et al., 2017). The cloud literature focuses more on the associated technical issues of with less attention paid to business issues regarding the adoption of cloud (Lian et al, 2014; Brender \& Markov, 2013). A wider consideration of the challenges and risks should be taken into attention before switching to a cloud infrastructure (Lian et al., 2014; Hsu et al., 2014).

\subsection{Supply Chain Responsiveness (SCR)}

There is a profusion of different definitions and dimensions of supply chain responsiveness (SCR) in the literature. SCR refers to the ability of a supply chain to respond to market demand in time effective manner (Christopher, 2016). SCR has been classified according to several dimensions, such as customer sensitivity (Van Hoek et al., 2001), demand transparency (Catalan and Kotzab, 2003), supply chain response lead-time (Holweg, 2005), agility (Blome et al., 2013), flexibility (Kim et al., 2013), information sharing (Handfield and Bechtel, 2002). The underlying themes that are common to the majority of classifications found in the literature of SCM can be classified into three fundamental dimensions of SCR. The recent study of Gonul Kochan et al. (2018), has 
highlighted multiple challenges of the SCR and tried to show that cloud-based information sharing improves the SC visibility in healthcare supply chains and therefore improving the whole SCR.

SCR denotes the speed of supply chain to deliver demand and can be measured in terms of order fulfillment cycle time (Supply Chain Council, 2012). If customer demand can be perceived without distortions and latencies, then companies have more chances to fulfill the orders successfully. The visibility of information across the supply chain is, therefore, a principal dimension of SCR as it increases demand sensibility by allowing every organisation along the supply chain to access the required information with transparency (Chengalur-Smith et al., 2012; Singh, 2015).

The inherent uncertainty of supply and demand and associated supply chain risks stipulate the need to be able to swiftly change the product mix, volume, delivery sequence, and supply capacity. Rapid detection of supply chain risks and swift decisions to mitigate them can, therefore, enhance SCR. Therefore, the second dimension of SCR is the rapid detection and reaction to supply chain risks.

The third dimension lies in the capability of a supply chain to demonstrate significant flexibility to adapt to demand uncertainty by restructuring its operations, reconfiguring its capabilities, or realigning its strategic objectives (Reichhart \& Holweg, 2007). Information integration amongst supply chain partners can enhance supply chain process integration and flexibility through joint planning, decision-making, and execution in a standard system. An IT system that is able to reconfigure dynamically supply chain processes according to the changing requirements can enhance supply chain flexibility. A modularised and service-oriented architecture can enhance the overall system flexibility by enabling rapid system integration and process configuration (Sambamurthy et al., 2003).

In traditional models of Information Technology and Systems such as enterprise resource planning (ERP), supplier relationship management (SRM), and customer relationship management (CRM); supply chain efficiency is promoted, the timeliness is increased, and accuracy of shared information is confirmed as well as the coordination and collaboration are improved (Kumar et al., 2017; Fayoumi, 2016). However, their benefits are often limited only in a single organisation, or a limited part of the supply chain (Verwijmeren, 2004). Their organisation-central architecture often increases the complexity and costs to exchange information with trading partners and has less flexibility to accommodate changes in supply chain structure (Poirier, 2003; Fayoumi, 2016). In order to achieve end-to-end visibility and high-level collaboration, the SCM application system should cover several participants of a supply chain. Furthermore, with the on-premise deployment mode, traditional integration represents a point-to-point pattern, which requires extensive integration interfaces between each organisation and its partners. The use of Radio Frequency Identification (RFID) technology can provide a solution to some of these issues by enabling realtime visibility, eliminating the latency introduced by human intervention, thus increasing responsiveness. However, challenges such as implementation cost (Lee and Park, 2010), replacing tracking system, different standards, (Ngai and Gunasekaran, 2009), voluminous data processing, and timely decision-making (Tiwari et al., 2013) limit its full deployment for SCM

\subsection{Cloud-based Approaches: Implications for Supply Chain Responsiveness}

Within a manufacturing context, cloud utility model is increasingly gaining attention within the recent years as one of the major enablers for the manufacturing industry (Babiceanu and Seker, 
2016; Helo et al., 2014; Shamsuzzoha et al. 2016; Schniederians et al., 2016). Industrial applications of the cloud are often addressed within manufacturing literature under the term of 'cloud manufacturing' (Helo and Hao, 2017); which is defined as the "model for enabling ubiquitous, convenient, on-demand network access to a shared pool of configurable manufacturing resources" (Xu, 2012). Cloud-based operations management allows firms to request various services ranging from product design, manufacturing, testing, management, and all other stages of a production planning and lifecycle management (Wu et al., 2013; Xu, 2012). Cloud service models share five common essential characteristics that distinguish cloud from other computing technologies (Mell and Grance, 2011) namely: a) on-demand self-service, b) broad network access, c) resource pooling, d) rapid elasticity and e) measured service. These characteristics can be extended to the many implications for the Supply Chain Responsiveness (SCR) context as it is described in Table 1 .

Table 1 - Implications of Cloud in Supply Chain Responsiveness

\begin{tabular}{|c|c|c|}
\hline $\begin{array}{l}\text { Cloud } \\
\text { characteristics }\end{array}$ & Description & Implications for Supply Chain Responsiveness \\
\hline $\begin{array}{l}\text { On-demand } \\
\text { self-service }\end{array}$ & $\begin{array}{l}\text { The consumer can unilaterally } \\
\text { provision computing capabilities, } \\
\text { such as server time and network } \\
\text { storage, as needed automatically } \\
\text { without requiring human } \\
\text { interaction with each service } \\
\text { provider. }\end{array}$ & $\begin{array}{l}\text { - IT capital expenses can become operational expenses by } \\
\text { renting an SCM system based on usage rather than purchasing } \\
\text { infrastructures and applications licenses. In that way, costs } \\
\text { become more variable and more in line with revenues (Jones } \\
\text { \& Schramm, 2011). } \\
\text { - By outsourcing maintenance and technical support to a cloud } \\
\text { service provider, organisations do not need to hire dedicated } \\
\text { technical staff to support the system (Schneider and Sunyaev, } \\
\text { 2016). }\end{array}$ \\
\hline $\begin{array}{c}\text { Broad network } \\
\text { access }\end{array}$ & $\begin{array}{l}\text { The capabilities are available } \\
\text { over the network and accessed } \\
\text { through standard mechanisms } \\
\text { that promote use by } \\
\text { heterogeneous thin or thick client } \\
\text { platforms (e.g., mobile phones, } \\
\text { tablets, laptops, and } \\
\text { workstations). }\end{array}$ & $\begin{array}{l}\text { - The organisation only needs to plug into the cloud, then it can } \\
\text { exchange necessary information and collaborate (processes } \\
\text { orchestration) with all its partners through heterogeneous } \\
\text { platforms (Jede \& Teuteberg, 2016; Shamsuzzoha et al., } \\
\text { 2016; Chengalur-Smith et al., 2012). } \\
\text { - The cloud integration interface supports open standard and } \\
\text { multiple data formats (e.g., EDI, XML, flat files), thus } \\
\text { facilitating rapid integration and real-time information } \\
\text { sharing (Helo et al., 2014). } \\
\text { - Advanced processing and storage capabilities to manage } \\
\text { supply chain requirements and transactions (Zhang et al., } \\
\text { 2014). } \\
\text { - Advanced techniques to understand and process variation of } \\
\text { demand and respond promptly (Zhang et al., 2010). }\end{array}$ \\
\hline
\end{tabular}




\begin{tabular}{|c|c|c|}
\hline $\begin{array}{c}\text { Resource } \\
\text { pooling }\end{array}$ & $\begin{array}{l}\text { The provider's computing } \\
\text { resources are pooled to serve } \\
\text { multiple consumers using a } \\
\text { multi-tenant model, with different } \\
\text { physical and virtual resources } \\
\text { dynamically assigned and } \\
\text { reassigned according to consumer } \\
\text { demand. }\end{array}$ & $\begin{array}{l}\text { - As services are delivered as a utility, organisations located } \\
\text { anywhere in the world can easily access them (Marston et al., } \\
\text { 2011). } \\
\text { - The rapid deployment and flexible information sharing } \\
\text { enable supply chain participants to coordinate and collaborate } \\
\text { to match the continuous changes in business processes and } \\
\text { community of trading partners (Helo and Hao, 2017; } \\
\text { Fayoumi, 2016). } \\
\text { - Identifying and extracting information content and aligning } \\
\text { and integrating extracted information to generate new or } \\
\text { innovative products/services (Helo and Hao, 2017; } \\
\text { Shamsuzzoha et al., 2016). }\end{array}$ \\
\hline $\begin{array}{c}\text { Rapid } \\
\text { elasticity }\end{array}$ & $\begin{array}{l}\text { Capabilities can be elastically } \\
\text { provisioned and released, in some } \\
\text { cases automatically, to scale } \\
\text { rapidly outward and inward } \\
\text { commensurate with demand. }\end{array}$ & $\begin{array}{l}\text { - can potentially provide virtual infinite computing scalability } \\
\text { that enables an SCM system to quickly and cost-effectively } \\
\text { scale up and down matching the dynamic process volumes } \\
\text { and the number of trading partners (Jones and Schramm, } \\
\text { 2011). } \\
\text { - Real-time supply chain responsiveness (Shamsuzzoha et al., } \\
\text { 2016). }\end{array}$ \\
\hline $\begin{array}{l}\text { Measured } \\
\text { service }\end{array}$ & $\begin{array}{l}\text { Cloud systems automatically } \\
\text { control and optimize resource use } \\
\text { by leveraging a metering } \\
\text { capability at some level of } \\
\text { abstraction appropriate to the } \\
\text { type of service (e.g., storage, } \\
\text { processing, bandwidth, and active } \\
\text { user accounts). }\end{array}$ & $\begin{array}{l}\text { - Any upgrade and enhancement are conducted in the cloud, } \\
\text { and any improvement of applications can be accessed } \\
\text { immediately by organisations (Marston et al., 2011). } \\
\text { - As fewer interfaces are required, the upfront integration and } \\
\text { maintenance costs and time of deployment are reduced } \\
\text { (Schneider and Sunyaev, 2016). }\end{array}$ \\
\hline
\end{tabular}

Previous research following the view of cloud-based approaches of operations management is mostly focusing on models for production optimization, decision-making and information and data flows across the supply chain (Helo \& Hao, 2017; Jede \& Teuteberg, 2016). Cloud approaches provide multiple advantages and benefits for the whole production lifecycle (Vazquez-Martinez et al., 2018); while identifying the logic behind the physical resource operation and translating it into the cyberspace in order to improve agility, enhance flexibility and reduce cost (Babiceanu and Seker, 2016); or even by improving efficiency, reducing lifecycle costs, and providing optimal resource allocations (Wu et al., 2013; Wu and Chiu, 2018). Cloud can potentially provide virtual infinite computing scalability that enables an SCM system to quickly and cost-effectively scale up and down to match dynamic process volumes and the number of trading partners (Jones \& Schramm, 2011). Any upgrade and enhancement are conducted in the cloud, and any improvement of applications can be accessed immediately by organizations (Marston et al., 2011). As services are delivered as a utility, organizations located anywhere in the world can easily access them and can globally provide a manufacturing service model for the supply chain partners (Grant and Yeo, 2018). The rapid deployment and flexible information sharing enable supply chain participants to coordinate and collaborate to match the continuous changes in business processes and community of trading partners (Helo and Hao, 2017). There is also recent research on the effects of cloud- 
based ecosystems in healthcare SC (Gonul Kochan et al., 2018), however there was a strong focus on the information sharing aspect and internal integration aspects of SCR (Manuel Maqueira, et al. 2018). Internal SCR can be enhanced through the use of cloud-based ecosystems (Gonul Kochan et al, 2018; Lal and Bharadwaj, 2016), however in the study herein we will focus on the interactions and aspects of SCR (dimensions) with the external environment (out of the boundaries of the focal firm).

\section{Research Method}

In this study, we develop a cloud-based SCM (C-SCM) approach; therefore we followed an exploratory rather than a confirmatory method to show the effects of a C-SCM on the three dimensions of SCR. A case study approach of a real company was utilised in a cloud-based environment, which involves common logistics activities of a selected company from the retail fashion industry located in London, UK (for confidentiality it will be called hereafter K\&E). A series of case scenarios were analysed to explore how the components of the proposed approach interact to improve supply chain responsiveness. The case study supports this research by identifying and familiarising with the organisational background, functions, relationships, processes and the architecture of the case company and by providing ground for refining and reshaping the initial C-SCM conceptual approach (e.g. Eisenhardt, 1989; Ketokivi and Choi, 2014). Building our C-SCM conceptual approach on a case study was deemed as the most appropriate in this topic area, as the links between the cloud and SCR are not clear yet, and is mostly researched from an internal responsiveness perspective (Gonul Kochan et al., 2018). Through the case study approach we will be able to provide freshness in perspective to an already researched topic from an external-responsiveness perspective.

\subsection{Case Study Background and Context}

One of K\&E's core products $(\mathrm{X})$ is produced at its manufacturing centre in Shenzhen, China. Raw materials are received from a local supplier. Both inbound and outbound logistics are outsourced to a 3PL company. The products are transported from Shanghai to Southampton UK by sea, and then the products flow through two distribution channels: through wholesalers for B2B sales and through retailers for $\mathrm{B} 2 \mathrm{C}$. The company has two DCs in the UK, one in Coventry, and one in Leeds and adopts consignment inventory model with its retailers. When goods arrive in the UK, a local logistics partner receives the containers and sends them to the deconsolidation operation centre, and from there the products are sent to the DCs. A local logistics partner sends the product to wholesalers and retailers.

\subsection{Sampling Strategy}

Data has been primarily collected through in-depth semi-structured interviews. The participants were of a high stature within the companies in the supply chain. 25 managers were interviewed in total. Of those, $60 \%$ were senior executives including the director of the company's UK operations. In order to avoid a polarised perspective, a number of more junior managers were also chosen to offer complementarities and comparison. All interviews were recorded and transcribed and then analysed through the development of a codification system for supply chain responsiveness. All the interviewees participated voluntarily, and it was agreed that their details would be kept confidential, so the companies are referred to throughout this paper by pseudonyms. The interviews lasted between 60 and 90 minutes. Analysis of documents relating to purchase orders and logistics 
activities and performance was also used as a supporting data collection process to triangulate data from the interviews. It allowed a more objective perspective to be generated that was free from individual opinions.

\section{A Cloud-based SCM (C-SCM) system}

For the development of the initial approach of a cloud-based SCM (C-SCM), we adopted a sequential analytical method. First, we formulated the generic inter-organisational design and embedded in an overarching cloud-based platform. Then we defined the roles of each of the modules within the c-SCM, and generated a detailed description of their responsibilities. The interaction between these modules was subsequently modelled by analysing several example case scenarios.

Figure 1 presents the essential elements of a C-SCM for a multi-enterprise SCM. This model comprises three stakeholders: an infrastructure provider, a service provider and the trading community (service consumers). The SCM service provider is responsible for the design, development, deployment, information processing, maintenance of a cloud-based SCM system, and delivers applications as services via the internet to multiple SCM service consumers. The services are paid on usage or time basis, and the quality of service is also guaranteed through SLAs. The cloud-based SCM can provide both PaaS and SaaS products. PaaS products involve a series of applications and tools to facilitate new application design, development, testing, and deployment as well as data integration and processes management (Baun, 2011). SaaS products form the core part of the C-SCM and accessed by the most of SCM service consumers. They include a broad range of SCM applications, such as collaborative demand forecasting, replenishment, manufacturing planning and logistics tracking. All applications in the C-SCM are designed and deployed as services, thus facilitating reuse and consumption by other applications. The focus of this paper is primarily on the cloud-based SCM approach. SCM service consumers represent the customers. All these business entities virtually constitute a trading community which allows each member to operate, share information and collaborate on the same platform.

Figure 1 - Overview of Cloud-based SCM (c-SCM)

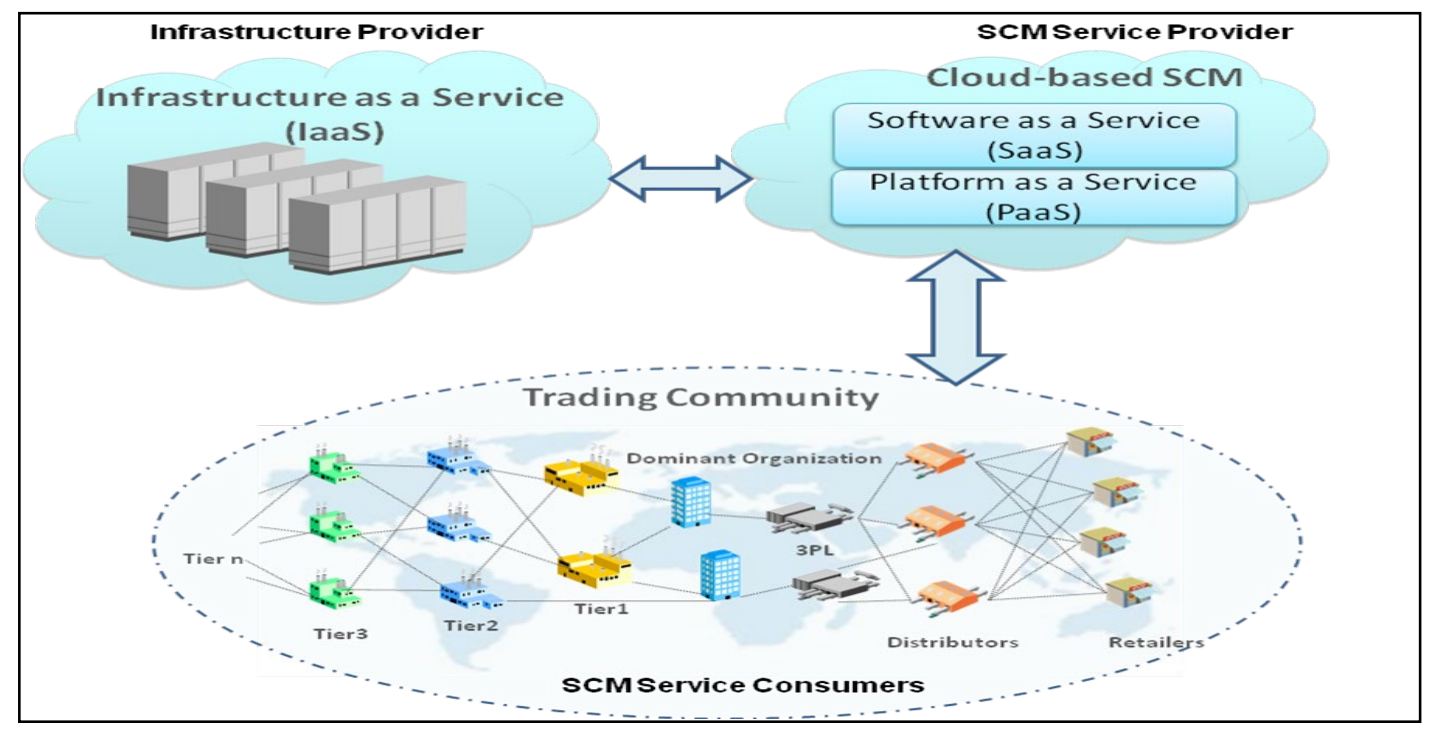


The proposed C-SCM approach can be deployed as a closed community cloud to ensure security and data privacy. The target consumers of the C-SCM are organisations with close business relationships, same objectives (e.g., real-time information sharing, collaboration, visibility) and concerns (e.g., security and data privacy). Compared to a public cloud, a community cloud can provide services compliant to a standard agreed by all consumer organisations, more negotiable forms of SLA, a higher level of customised services and processes, and higher degree control over data (Wald, 2010). Unlike a private cloud, it cloud can achieve significant capital as well as operational savings in both IT infrastructure establishment and maintenance.

The C-SCM approach as depicted in Figure 2 focuses on the SCM service provider system and develops the main architecture; the capabilities of each component of the system and the interactions between them are discussed. The approach is composed of six separate modules.

Figure 2 - Cloud-based SCM (C-SCM) Architecture

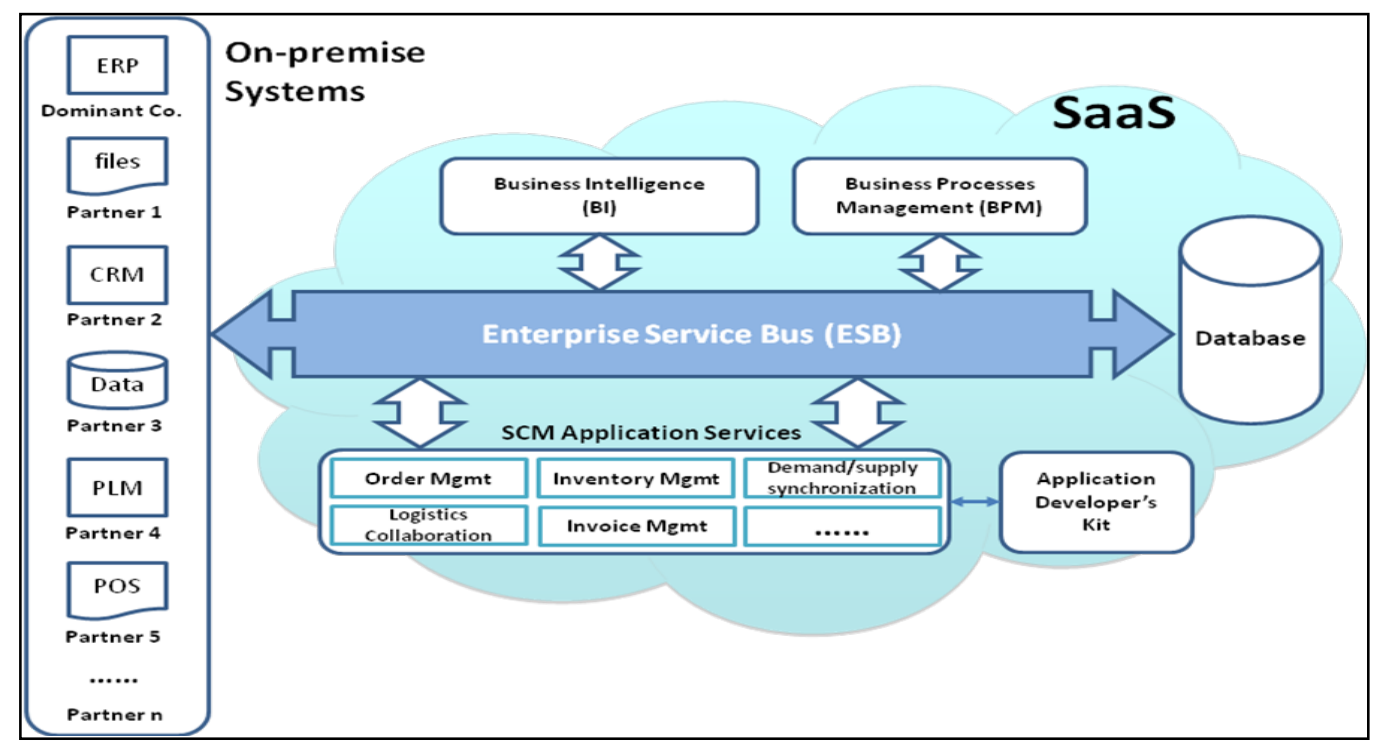

\subsection{SCM Application Services}

This module is a pool of numerous SCM applications and services, which represent the core service deliverables of the C-SCM. All applications are deployed as loose-coupled services, complying with SOA software design pattern. For example, an 'Inventory Checking' can return the inventory status on customers' enquiries. At the same time, this application can provide other services (e.g., inventory report, dashboard) or processes (e.g., replenishment, demand forecasting). These applications can be used and reused without limits, to facilitate rapid application development. This architecture provides the potential of dynamic inter-organisational process modelling and configuration. Cloud clients can access these application services via standard interfaces (e.g., web browsers), and set the accessibility of the service under role and privilege control. As the C-SCM is shared with customers and most of them may be already equipped with ERP systems, it focuses on providing applications with lower complexity, involving more commoditised processes, intensive interaction and collaboration with multiple trading partners. This may involve procurement and sourcing, collaborative forecasting, collaborative replenishment, VMI, logistics management, or promotion management processes. 


\subsection{Application Developer's Kit (ADK)}

This module is the main component of a PaaS product delivered by the SCM service provider. It involves a set of application development tools that allows cloud clients to design, develop, test and deploy their own customised applications. Its main target users are IT staff within customer organisations. The development tools can adopt a developing graphical interface and supported by a technical library. Within the technical library, a large group of underlying services is included as service components for the further application. These service components involve every aspect of application design and development, including integration, database, security, user interface, and application logic. With the help of service components, developers do not have to develop from scratch. The technical library also includes other resources, such as documents and technical guides, or sample codes.

\subsection{Enterprise Service Bus}

The C-SCM operates as a platform on which organisations can interact and collaborate with their trading partners in real time. For that reason, it is vital to collect and distribute real-time information to on-premise systems in different organisations. The C-SCM employs technologies that facilitate integration with disparate distributed applications and services within various systems. The integration facilitates SOA and supports various legacy applications as well. To improve SCR, the implementation of integration should be flexible, rapid and easy. An enterprise service bus (ESB) module can perform these tasks.

An ESB is an open standard and message-based integration infrastructure that can effectively and efficiently facilitate the integration of disparate distributed applications and services within various organisations (Schmidt et al., 2005). Any service registered onto the ESB can be easily consumed or triggered by other services, applications, or events. The ESB supports various application interactions model, including requests and responses, synchronous and asynchronous, publish and subscribe, and various event processing models (Maréchaux, 2006). Figure 3 depicts a typical integration pattern between the C-SCM and on-premise application systems.

Figure 3 - System Integration by ESB

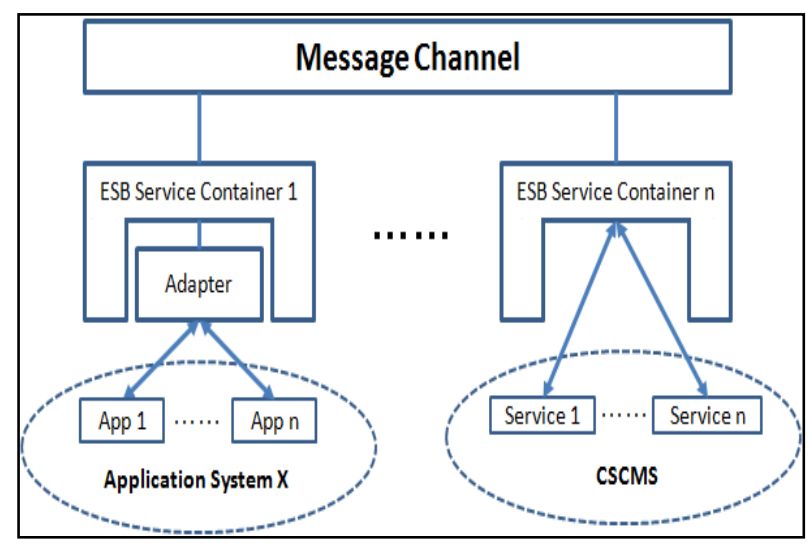

The proposed ESB consists of a number of distributed service containers which are interconnected over a reliable and secure messaging channel. Each service container is responsible for connecting a certain number of applications or services and hosts a series of integration services. An adapter, which is a service connector that links various (on-premise) proprietary application packages (e.g., 
ERP, CRM), can be used. These business systems normally expose certain standard interfaces in the form of native transaction interfaces and certain data structures. The adapter is able to use these interfaces to transform messages between the service container and systems or services. The ESB can provide a whole range of service adapters for various popular systems and services. The ESB provides several integration services within each service container, including an invocation, routing, and mediation, thereby accelerating loose-coupled integration (Menge, 2007). This interoperability and distributed architecture of ESB facilitates integration with a broad range of heterogeneous application systems residing in organisations and enables them to set up information integration easily.

\subsection{Database}

This module is responsible for storing and retrieving data that is used in C-SCM. It involves two components: a storage and a database management system (DBMS). The storage is where the data is stored in and retrieved from. It is provided by the infrastructure provider within its IaaS services. The space of storage is provided in an on-demand manner through a large pool of storage devices (e.g., physical disk and main memory) installed in its data centres. The DBMS is a software system that mediates storage and users or other applications. It uses a standard method to store into and retrieve data from storage on request of people or other applications. Three main types of data are stored in the database: transactional data (e.g., purchase/shipping orders, invoices.), master data (e.g., bill of materials, logistics route definitions) and metadata (e.g., configuration data, business rules repository, KPI repository).

\subsection{Business Intelligence}

The need for real-time monitoring, analysis of information and quick response to supply chain risks, necessitates the use of a business intelligence module. This module provides a group of applications and tools for managers and business users to monitor supply chain performance and conducts various data analyses to capture business trends, make decisions, resolve problems, as well as optimise business processes (Dubey et al., 2019; Azvine et al., 2006). The analysis and reporting conducted are based on real-time data collected from various trading partners and history data stored in the database. The Business Intelligence module is the bridge with the Big data analytics modules and can provide multiple additional opportunities for the SCM (Ashrafi et al, 2019; Dubey et al., 2018). This module includes four sub-modules: KPIs management, dashboard, reports, and analytics tools.

The KPIs Management sub-module generates and maintains various KPIs data and business targets used for performance monitoring and reporting. It provides graphical tools that help managers and business users to define KPIs and business targets and could include data from all the supply chain partners. All KPIs and business targets are stored in KPIs repository. KPIs and business targets are used when designing business rules of BPM.

The dashboards module is a data visualisation tools that provide an intuitive overview of what is happening in the supply chain. It consolidates a collection of analytics on arranged metrics, KPIs, as well as performance scorecards on a single screen. It enables users to efficiently and proactively capture trends and find exceptions in their supply chain as they occur, thus giving organisations the advantage of rapid reaction time. 
The Analytics module provides tools and applications that facilitate business users to conduct dynamic data analysis. Data mining tools represent a typical analytics tool that enables managers or business users to derive insights into business trends, event and low-performed processes through analysing a large volume of business data (Azvine et al., 2006). It enables organisations to find the root cause for problems and exceptions or patterns that may be valuable for future risks and opportunities, and facilitate timely decision-making.

The Reports module provides various business reports and report design and development tools, as well as templates to rapidly generate new reports. These reports reflect a wide range of SCM indicators, such as on-time delivery, fill rate, and forecast accuracy. Business users can generate their reports without technical staff's involvement.

\subsection{Business Processes Management (BPM)}

The BPM module performs a critical role in the proposed C-SCM. It enables organisations to design, execute, monitor, control, analyse and optimise business processes within the supply chain (Gartner, 2013). The processes may involve raising purchase orders, requests for quotations, order fulfillment, price negotiations, delivery of goods, etc. A process itself could also be encapsulated as a service that is consumable by other processes, to compose complex business transactions.

With the use of loose-coupled architecture enabled by SOA, the BPM module allows supply chain partners to model and deploy their own business processes, by simply composing different services. In this way, responsiveness and flexibility are improved by aligning rapidly supply chain business processes with market changes or best practices. By leveraging the real-time integration platform provided by the ESB, the BPM can facilitate business processes collaboration across organisations and enable business users to gain visibility and insight into real-time process performance. The BPM module is composed of three components.

The Business Processes Modeling and Design tool enables business users to dynamically design and customise SCM business processes across various organisations within the supply chain. A business process is composed of a sequence of various application services, using on certain rules. These services include both services from SCM application services module and systems from various trading partners that are integrated with the help of the ESB module. Business rules govern the way that these services are composed to generate expected outcomes. They are statements that describe key policies, regulations and decision logic of business. For example, an organization can define one of its discount rules as "customers that spend over a certain amount in one transaction will receive a $10 \%$ discount", and decision logic as "when the primary supplier shipment notification is late for over one day, then send request(s) to alternate supplier(s)".

The decision logic is virtually a knowledge base that enables C-SCM to achieve automatic decision-making by predefining some smart decision logics or recording previous successful resolution for future similar scenarios. Thus, it gives C-SCM a learning capability. The rules are stored in the business rule repository. They can be written in a standard, and readable language (e.g., BPML), and are executable through the BPM engine. They allow business users to reconfigure dynamically business process to realise certain business requirements, without having to involve IT staff and redeploying processes. That could eliminate the latency between business requirements initialisation and technical realisation. Moreover, a collection of best practices can be provided in rule templates to simplify implementation. With these functions and enabled 
capabilities, this module could effectively exploit the flexible services architecture and real-time integration platform to realise the capability of rapidly business processes creation and reconfiguration.

The Business Rule Repository is a database of various business rules. The Business rule repository and the KPI repository are interconnected so that the various KPI definitions can be used in defining business rules, and $\mathrm{BI}$ can use decision logic for automatic decision making as well. The BPM Engine is a software component that executes, administrates and monitors various business processes in C-SCM. The main responsibility for the BPM engine is to ensure that the correct services are invoked in the correct sequence. To do that, the BPM engine interacts with the ESB which takes the responsibilities to route the messages and invoke target services. The BPM engine also monitors and detects various process exceptions and events based on business rules. With the BPM engine, all players of C-SCM are able to track the real-time flow of goods, finance, and information across the network.

\section{Implications of C-SCM on the SCR Dimensions - An analysis}

In the previous sections we discussed the multiple implications of a cloud approach for the SCM, and how this approach could enhance the responsiveness of the Supply Chain (SCR). The section herein provides an analysis linking the C-SCM to the three dimensions of the SCR. A three-step analytical process has been followed to examine effects of the C-SCM on SCR. First, the existing mode of the supply chain operations under investigation were identified, as well as areas of underperformance of the existing operations. The final step involved the identification of typical supply chain scenarios with the help of managers of the firms and subsequently the incorporation of the use of the C-SCM, to explore the extent of which the three dimensions of SCR are affected. Our inductive case study process follows the steps of Eisenhart (1989):

- Onsite analysis during data collection

- Initial analysis of transcription of interviews, document summaries, and observation notes.

- Focus analysis of emerging themes and initial categorisation (coding)

- In-depth analysis, comparing findings with concepts in the literature to generate themes and to identify relationships

- Discussion of analysis with sample of interviewees

- Presentation of the results to the company to ensure the validity and reliability of the study.

The results are presented in terms of the effect of the incorporation of the proposed C-SCM on the three dimensions of SCR.

\section{Real-Time End-to-end Visibility}

With the ESB module, the C-SCM integrates all organisations' back-end systems (e.g., ERPs) and devices (e.g., mobile, GPS). Figure 4 depicts the integration overview for K\&E's supply chain. The large range of adapters ensures that the ESB can "talk" to various systems and applications. The route and mediation services enable systems' integration to be loose-coupled (without the need of hardcode). Each organisation only needs to maintain an interface with the C-SCM. Up-todate information is always maintained in the C-SCM's database, which is accessible to all participants through the ESB. In this way, data latency that is caused by manual intervention is 
reduced, and end-to-end supply chain visibility regarding material movements, as well as current and projected inventory levels, are provided.

Figure 4- Integration of Heterogeneous Systems through ESB

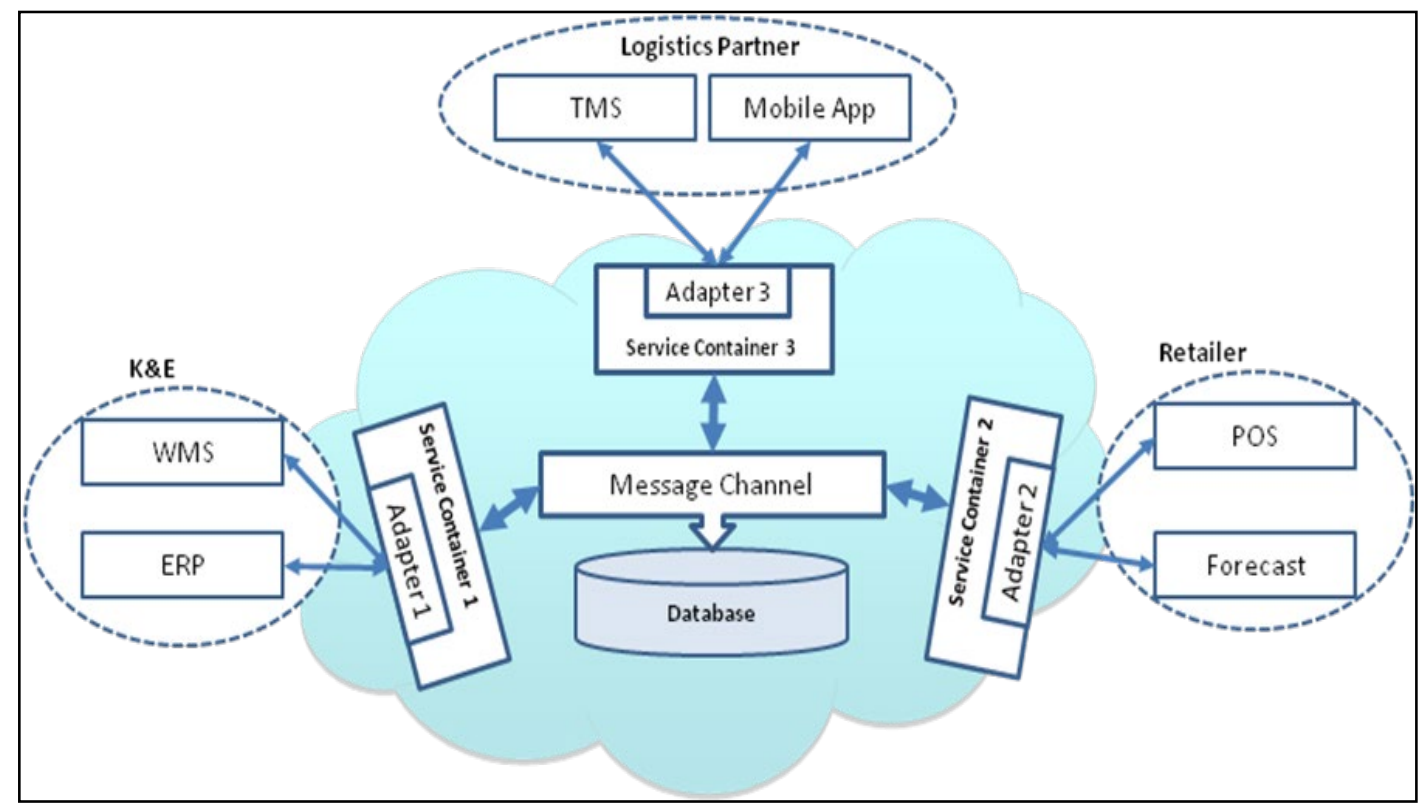

Figure 5 illustrates the implication of the proposed C-SCM in the company's logistics process with material and information movements. The C-SCM lies in the core of the logistics process.

Figure 5 - End-to-end Logistics visibility

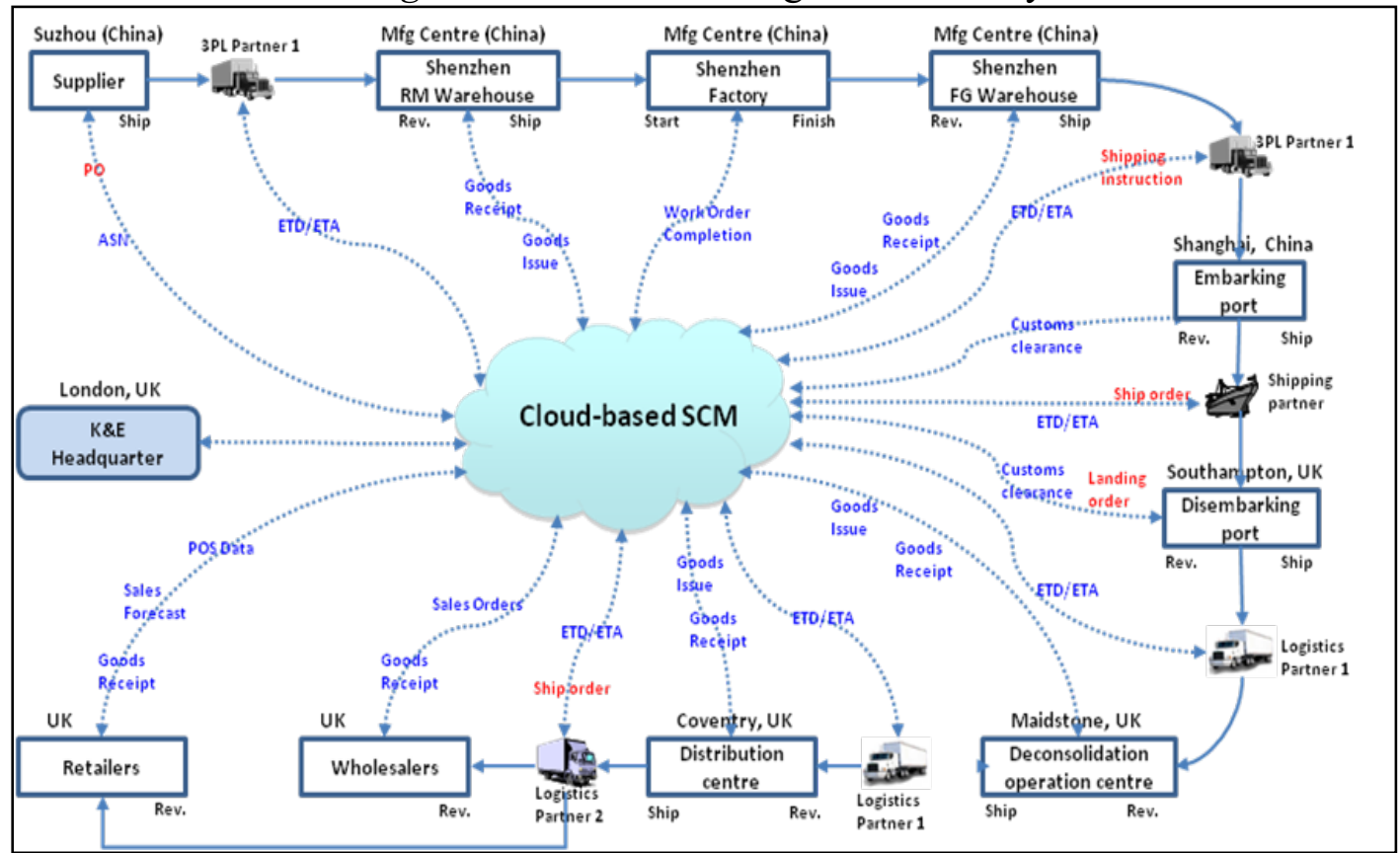


When the supplier receives a purchase order, it sends an advance-shipping note to notify the raw materials warehouse in Shanghai of the expected arrival time. The projected inventory of raw materials at the warehouse is then calculated. As the 3PL partner loads the raw materials from the supplier, the route definition, the estimated (ETD) or actual (ATD) time of departure are submitted on the C-SCM and the estimated time of arrival (ETA) is continuously updated during the transportation, using tracking GPSs installed in trucks. With this information, the projected availability of raw materials in the manufacturing centre can be predicted, and the production plan can be generated accurately. Once the raw materials arrive at the warehouse, the reception is synchronised with the C-SCM in real time. The production system is also integrated with the CSCM. Thus the latest production information (e.g., production schedule, work in process and work orders completion) is available to all supply chain partners. The transactions of receiving, reserving and shipping the products to the finished goods warehouse are also tracked by the C-SCM. The available inventory in the finished goods warehouse is visible at any time to the headquarters who can promise the delivery date for any incoming demands.

Based on shipping instructions, the 3PL partner delivers the products to Shanghai. The route definition, ETD, ATD, and ETA are updated on the C-SCM. The subsequent logistics nodes are then automatically notified of the ETA and the projected products' availability of can be predicted. The detailed status of customs clearance and the ETD/ETA of shipping are also updated continuously. When the containers arrive in Southampton, and the customs clearance process is completed, the logistics Partner1 is notified to collect the containers and deliver to the deconsolidation centre. The products go through several stages before being dispatched to the DC, including unloading, break bulk, cross-docking, packaging. Several transactions (e.g., goods receipt and goods issue) are automatically synchronised with the C-SCM. Then, the logistics partner1 delivers the products to the DC. The transactions of receivable goods are synchronised with the C-SCM automatically, enabling visibility of inventory levels by the downstream lings in the supply chain. The logistics Partner2 is then notified to deliver the products to various wholesalers and retailers according to sales orders and sales forecasts. Both logistics partners are authorised to update the ETDs/ETAs during the transportation process. When the wholesaler receives the goods, the transaction of receivable goods is submitted to the C-SCM. The corresponding sales order's status is then changed to 'delivered,' or its open quantity is deducted from the delivered quantity. The C-SCM is also integrated with the point of sale systems of the retailers, making their inventory levels and demand records visible to the headquarters and DC at any time.

\section{Proactive Risk Detection}

The C-SCM can dynamically monitor various performance factors such as ETAs, ETDs, projected inventory, estimated KPIs. This provides the basis to proactively detect disruptions and operational risks. The centralised architecture of the system enables performance information to be readily available to various participants in real time. Supply chain partners can then adopt collective proactive resolutions rapidly. Figure 6 illustrates an example of proactive detection of delay in K\&E's logistics processes. 
Figure 6 - Illustration of a Shipment Delay

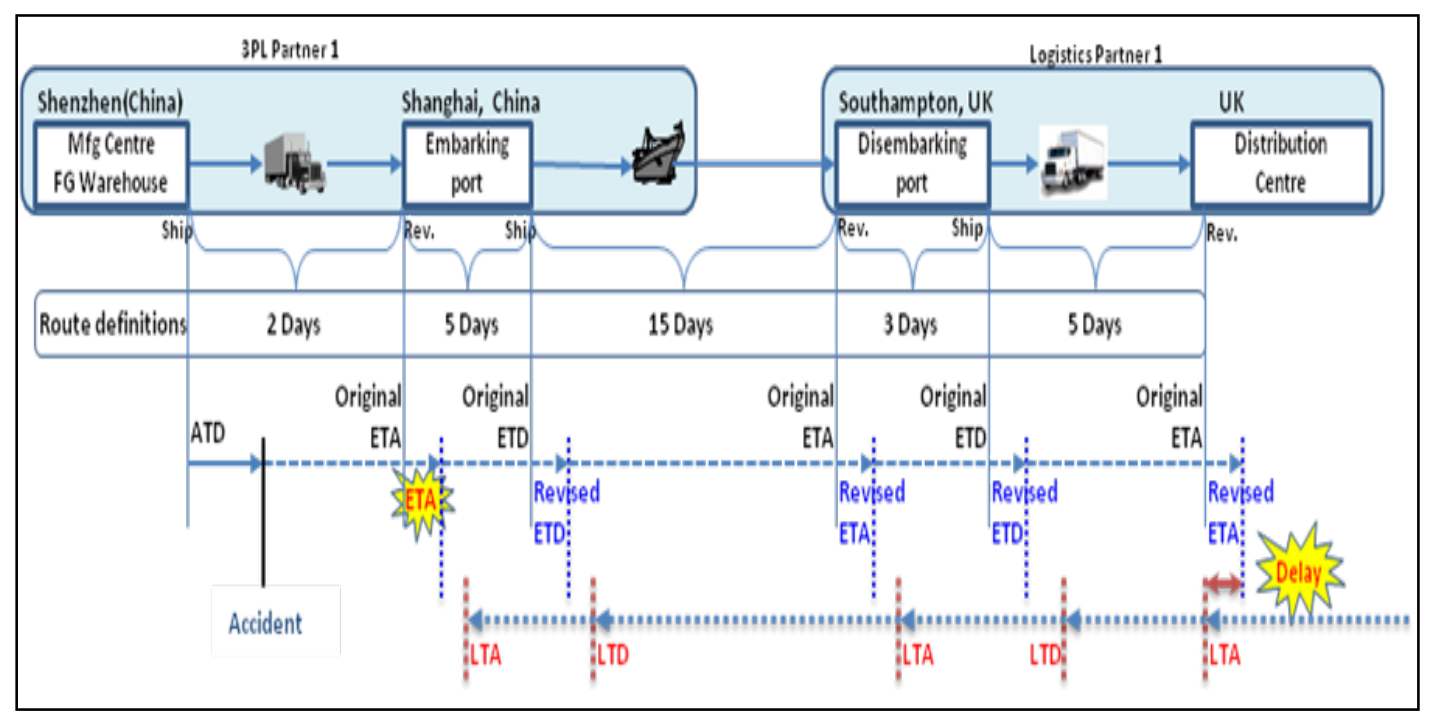

A shipment (DE-000) is in transit from the finished goods warehouse to Shanghai port by the 3PL Partner1 for fulfilling a sales order (SO-1) from a wholesaler. The average time required for transportation from the warehouse to Shanghai is 2 days, and 30 days are needed to reach the DC. Based on the route definitions, the C-SCM can automatically predict the ETAs and ETDs for each stage, based on the ETD or ATD at the immediate preceding stage:

$$
\text { ETA at Shanghai port }=\text { ATD at FG Warehouse }+2 \text { Days. }
$$

The latest time of arrival (LTA) and latest time of departure (LTD) refer to the latest time the shipment can arrive and depart from a given location so the due date of demand can be met. They are calculated backward, for example:

\section{LTA at DC = Sales order due date - Least processing time - Transportation time.}

With the same logic, the LTA and LTD at each logistics node are calculated backward, stage by stage. If ETA > LTA at a specific location, then the C-SCM detects delay. By taking into account the level of confidence for projected inventory levels and the sensitivity of the detection of a delay, the C-SCM can allow time requirement definitions for forward (ETA and ETD) and backward (LTA and LTD) calculations to be defined in different values for the same route. For example, if the average time plus the highest degree of the buffer is used for forward calculation, the projected availability will be with high confidence. If a more optimistic estimated time requirement with fewer buffer is used for backward calculation, then the delay detection would be less sensitive and may be too late to adopt any remedy.

The example below shows how the C-SCM would operate in the case of a supply chain disruption. In the way to Shanghai port, a serious accident occurs. The 3PL Partnerl evaluates the situation and estimates that one more day would be required to reach Shanghai. Figure 7 illustrates the process of delay detection by the C-SCM. 
Figure 7 - Schematic Illustration of Proactive Risk Detection Process

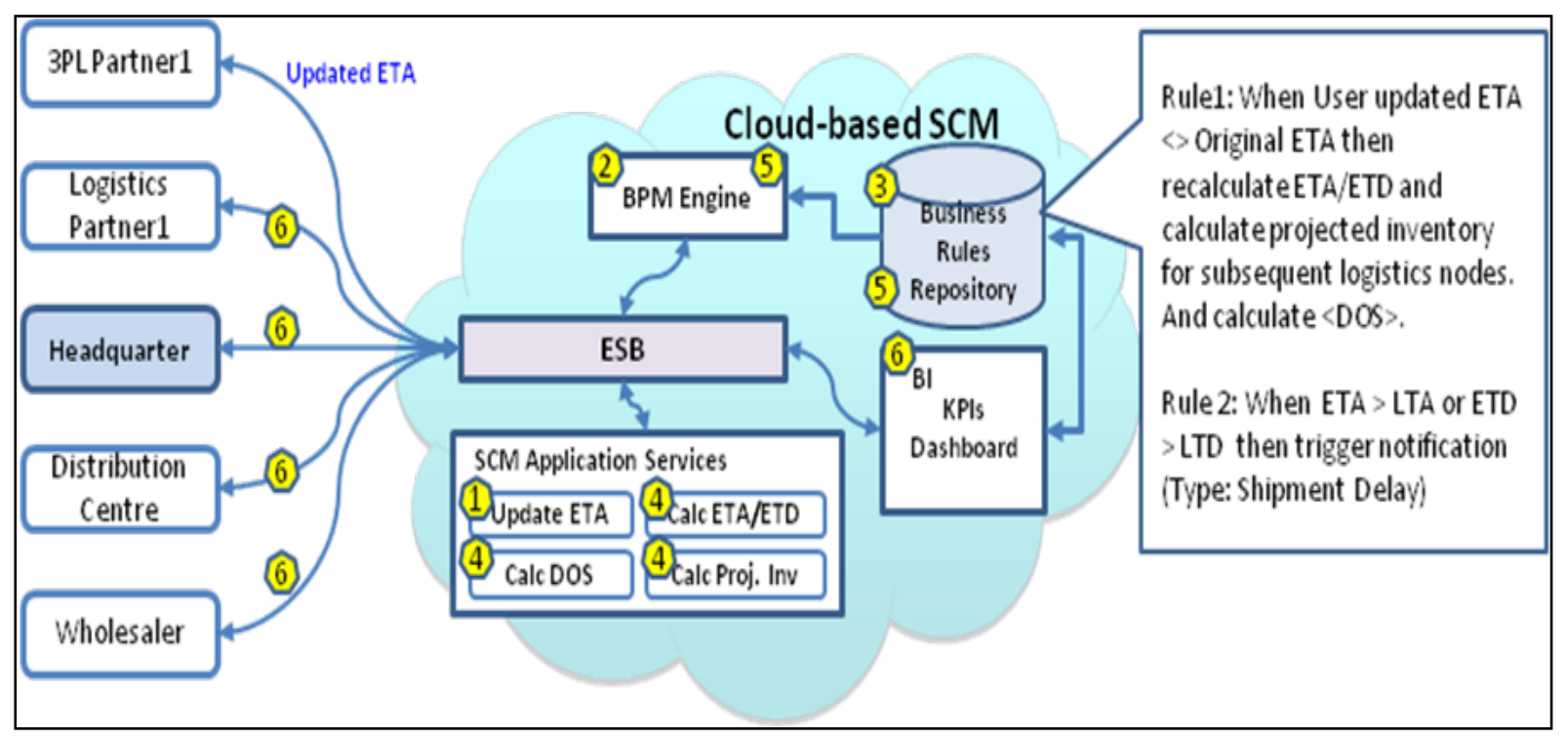

The driver immediately posts the updated ETA at Shanghai through the mobile application for this shipment. The ESB then delivers the message of the updated ETA to the BPM engine, which monitors the process execution and detects various exceptions and events. Based on the process definition, the BPM engine checks the business rules associated with this transportation, from the business rules repository. Since the revised ETA of Shanghai is 1 day later than the original, it satisfies the condition of Rule1. In this case, the BPM Engine submits a message to the ESB to trigger a new process of calculation of ETA/ETD and projected inventory levels at subsequent logistics nodes, as well as days of supply (DOS) for specific logistics node defined in BI. When the new process updates the ETA for the DC, the BPM engine detects that the revised ETA at the DC satisfies the condition of Rule 2. Then it sends a request to the ESB with the required information, e.g., notification type, priority, recipients, description (Table 2). The ESB then transforms the alert message to notify the shipment delay to the related recipients and invokes the notification service to trigger a dashboard update. Any participant who has the privilege can find this notification from the dashboard in the BI module.

\section{Table 2. Structure of a Notification Message}

\begin{tabular}{|c|c|c|l|}
\hline Type & Priority & Recipients & \multicolumn{1}{c|}{ Message } \\
\hline Warning & High & $\begin{array}{c}\text { Headquarter, DC, } \\
\text { Wholesaler, Logistics } \\
\text { Parnterl }\end{array}$ & $\begin{array}{l}\text { The delivery of sales order (SO-001) is likely to be delayed for 1 } \\
\text { day because the shipment (DE-000) is expected to arrive at DC } \\
1 \text { day later than required. }\end{array}$ \\
\hline
\end{tabular}

In this case, the notification of delay is prompted 30 days before it actually happens at the DC, enabling proactive decisions, such as changing routes or transportation means. Using the same logic, various KPIs are examined continuously to proactively detect risks of business performance suffering by designing specific rules.

\section{Flexibility through intelligent decision making}

In order to appropriately tackle the complexities and uncertainties associated with supply chain responsiveness stakeholders often applied decision-making tools and techniques. By leveraging 
some intelligent rules and exception knowledge base, the C-SCM could acquire automatic decision making when detecting risks. A flexible C-SCM can unleash the capabilities not normally afforded to the stakeholders using decision-making tools in isolation. Flexibility through intelligent decision making enables the acquisition of proactive risk detection and Real-Time End-to-end visibility.

The K\&E logistics system in a C-SCM approach can provide intelligent decision-making for the two DE-001 and DE-002 shipments which are on route to the UK to replenish inventory for DC A and DC B respectively. One KPI, days of supply (DOS) is a key indicator to evaluate the inventory position for the DCs. The company can dynamically calculate the projected DOS through the CSCM intelligence tools to detect if there is a potential shortage and set the lower limit value to be 7 days, and the control fence time 15 days. Thus, any projected DOS that runs below 7 days within 15 days, will initialise a warning as well as decision-making process. These settings are stored in the KPI repository in the BI module. Figure 8 depicts a conceptual representation of the system.

Figure 8 - Conceptual repetition of the K\&E logistics case study

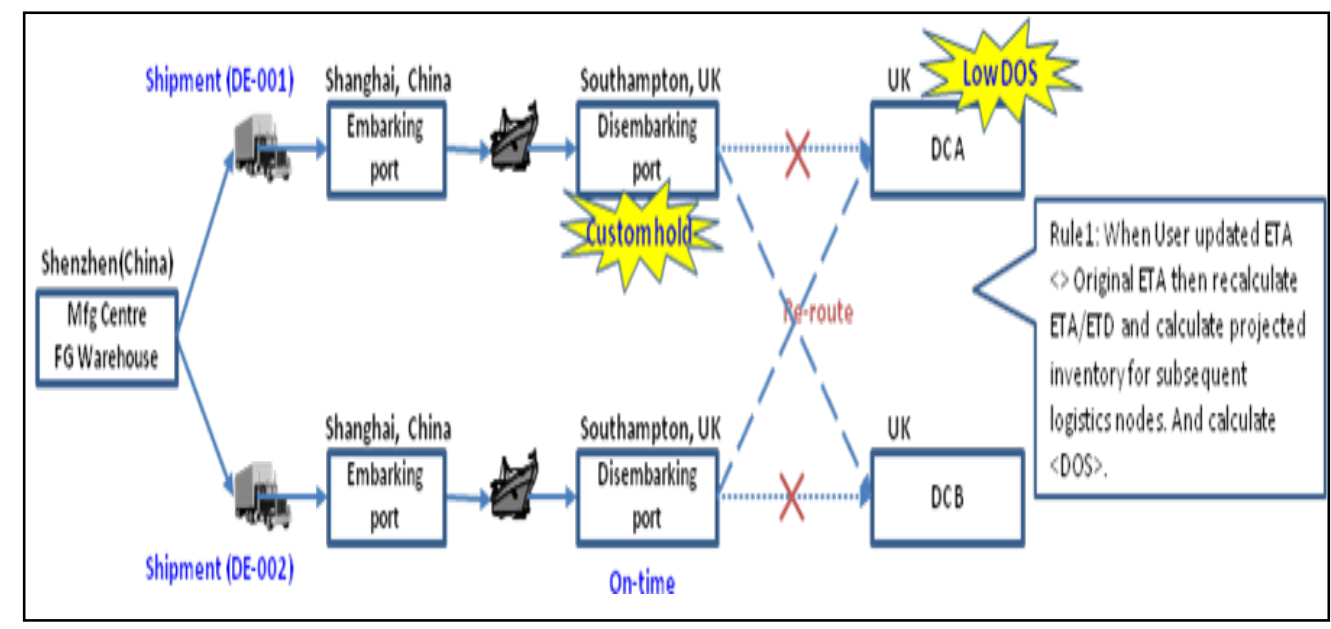

When the shipment DE-001 arrives at Southampton, it is held by customs for a compliance check. This results in two days' delay. In the case that shipment DE-002 finished the process on time, the logistics Partner1 submits the updated ETA to be two days later at DC A for shipment DE-001. At the same time, the BPM Engine receives the update and explores associated business rules with this process. Since it satisfies the condition of Rule1, the BPM Engine invokes a new process to recalculate ETAs, ETDs, projected inventory, and DOS. After the calculation, the updated DOS falls below 7 days in the control fence time. The BI thus detects the risk of low DOS for DC A. With this process, the BI module can identify automatically whether there are resolutions for this problem defined in Business rule repository. The structure of decision logic is depicted in table 3.

Table 3. Structure of Decision Logics

\begin{tabular}{|c|c|c|c|c|}
\hline no. & Trigger & Risks & Potential Resolution Description & Process ID \\
\hline 1 & Low DOS & Shortage & $\begin{array}{l}\text { Re-peg shipments for replenishment order to reach } \\
\text { holistic minimum DOS violation. }\end{array}$ & PRL05811 \\
\hline$\ldots \ldots$ & $\ldots \ldots$ & $\ldots \ldots$ & $\ldots \ldots$ & $\ldots \ldots$ \\
\hline
\end{tabular}

Within the resolution knowledge base, the trigger, business impact, potential resolution as well as corresponding resolution process id are defined. For this case, the predefined resolution is provided 
to re-peg shipments. Thus, BI sends a message to ESB to invoke the predefined process of the resolution by its process ID number. With the re-peg shipments process, all DC replenishment requirements are prioritised, and all in-transit shipments are sequenced by ETA. Implications for theory and practice

Based on the conceptual grounding of SCR, the C-SCM approach and the analysis of the casebased scenarios, several implications for theory and practice can be drawn from this study. The proposed approach and the results of the case scenarios suggest a future research agenda for further exploration.

Theory suggests that there is a trade-off between SCR and supply chain complexity (Holweg, 2007, Swafford et al., 2008). Therefore, according to the trade-off theory, for an existing level of supply chain complexity, there is an optimal level of SCR that can be achieved. The main theoretical proposition of this study is that the use of a C-SCM approach can enhance SCR, despite the increased complexity of supply chains. As the proposed C-SCM enables IT real-time integration across complex supply chains, this leads to the greater responsiveness of the procurement and manufacturing processes that yields shorter lead times, despite the increased complexity of the supply chain.

The principal contribution for practitioners of this study is the development of a C-SCM approach which can improve the SCR. Our inquiry has demonstrated that the benefits of the adoption of cloud-based systems are not limited only to single companies that adopt them. The proposed CSCM approach provides integrated capabilities for enhancing supply chain visibility, identifying and reacting faster to operational supply chain disruptions and improving supply chain flexibility in a collaborative manner. Through the shared platform for disseminating supply chain information in real time and integrating with disruptive technologies (i.e. RFID, IoT, etc.) it allows supply chain partners to utilize IT resources and exchange information about their supply chains in a realtime and with a flexible manner.

The embedded facility of the ESB facilitates collaboration among supply chain partners. For example, when a customer confirms an order this information is available in real time to all the linked parties. A monitoring routine is enabled to allow for early identification of an abnormal event (such as production, or transportation delay). A corrective mechanism can be initiated immediately through established risk management routines. The proposed approach also has the potential to improve customer sensitivity through the identification and of trends of customer needs by the analysis of customer profiles and proactive operational planning

\section{Conclusion}

The global environment at the beginning of the 21 st Century has undergone a series of radical changes that exert great pressure on organisations, including fierce global competition, shorter product lifecycles, increasing customer expectation, fluctuating inventory and changing costs. Organizations have to demonstrate the greater capability to handle these challenges in order to stay competitive and continually survive in the market. To this end, they have to be responsive enough to satisfy customised and ever-changing demand from the market. Therefore, establishing a supply chain with great responsiveness has become a core strategy to gain a competitive advantage for most of the organisations. 
The paper fills a gap in academic research by proposing a reference approach for cloud-based SCM and shows how it can be utilised to improve SCR. The introduction of cloud provides potential benefits through several promising IT capabilities, converting them into services that can be consumed by widely dispersed organisations, in an on-demand and cost-effective manner. Thus, organisations do not have to purchase licenses of these IT resources, deploy them on their own servers and hire dedicated staff or team to maintain them. Cloud enables the traditional point-topoint integration mode to evolve to hub-and-spoke mode, which significantly reduces the number of integration interfaces. Thus, it facilitates rapid deployment and promotes real-time information integration and sharing. The on-demand scalability enables C-SCM to accommodate suddenly increased or decreased data volumes and trading partners.

With the utilisation of a C-SCM, a supply chain-wide knowledge learning, decision making, reaction, and optimisation can be achieved. The advantages of proposed C-SCM over conventional SCM approaches are a multitude. Real-time end-to-end supply chain visibility is the most promising one, which provides a basis for demand sensibility and various other capabilities. Collaboration between organisations can be improved by C-SCM. Flexibility in infrastructure level, application level, process level, partner relationship level and cost structure level are all improved. Various exceptions, disruption risks as well as business trends can be captured in real time. The knowledge learning capability can achieve a real-time reaction. C-SCM can be beneficial for several business processes, especially for those processes that widely dispersed or require intensive partners' collaboration, such as logistics management, purchase management, collaborative planning forecast, and replenishment, etc.

The future direction of this study is to conduct an experimental approach that measures the potential quantitative achievements (e.g., lead-time and operation cost reduction) that can be achieved by adopting the proposed approach. Future research could also study how organisations implement cloud-based approaches in order to have minimum impact on their business, and how service providers can improve cloud level interoperability in order to establish linked communities in the cloud.

\section{References}

Alshamaila, Y. Papagiannidis, S. and Li, F. (2013), "Cloud computing adoption by SMEs in the north east of England: A multi-perspective framework", Journal of Enterprise Information Management, Vol. 26, No. 3, pp. 250-275.

Armbrust, M., Fox, A., Griffith, R., Joseph, A.D., Katz, R., Konwinski, A., Lee, G., Patterson, D., Rabkin, A. and Stoica, I. (2010), "A view of cloud computing", Communications of the ACM, Vol. 53, No. 4, pp. 50-58.

Ashrafi, A., Ravasan, A. Z., Trkman, P., \& Afshari, S. (2019). The role of business analytics capabilities in bolstering firms' agility and performance. International Journal of Information Management, 47, 1-15.

Azvine, B., Cui, Z., Nauck, D. D., \& Majeed, B. (2006), "Real time business intelligence for the adaptive enterprise". In Proceedings of the 8th IEEE International Conference on and Enterprise Computing, E-Commerce, and E-Services, The 3rd IEEE International Conference on, pp. 29-29, IEEE. 
Babiceanu, R.F. and Seker, R. (2016), "Big Data and virtualization for manufacturing cyberphysical systems: A survey of the current status and future outlook", Computers in Industry, Vol. 81, pp. 128-137.

Baun, C. (2011), "Cloud computing: web-based dynamic IT services”, New York: Springer.

Bayramusta, M., \& Nasir, V. A. (2016). A fad or future of IT?: A comprehensive literature review on the cloud computing research. International Journal of Information Management, 36(4), 635-644.

Blome, C., Schoenherr, T. and Rexhausen, D. (2013), “Antecedents and enablers of supply chain agility and its effect on performance: a dynamic capabilities perspective", International Journal of Production Research, 51 (4), 1295-1318

Brender, N., \& Markov, I. (2013). Risk perception and risk management in cloud computing: Results from a case study of Swiss companies. International journal of information management, 33(5), 726-733.

Buyya, R., Yeo, C. S., and Venugopal, S. (2008), "Market-oriented cloud computing: Vision, hype, and reality for delivering it services as computing utilities", Proceedings of the 10th IEEE International Conference on High Performance Computing and Communications, Sept. 25-27, Dalian, China.

Catalan, M., and Kotzab, H. (2003), "Assessing the responsiveness in the Danish mobile phone supply chain”, International Journal of Physical Distribution \& Logistics Management, Vol. 33, No. 8, pp.668-685.

Cegielski, C. G., Jones-Farmer, L. A., Wu, Y. \& Hasen, B. T. (2012) "Adoption of cloud computing technologies in supply chains: An organisational information processing theory approach". International Journal of Logistics Management 23 (2): 184-211.

Chengalur-Smith, I., Duchessi, P. and Gil-Garcia, J. R. (2012), "Information sharing and business systems leveraging in supply chains: An empirical investigation of one web-based application". Information \& Management, No. 49, No.1, pp. 58-67.

Christopher, M. (2016), "Logistics and supply chain management". Pearson UK.

DeGroote, S. E., \& Marx, T. G. (2013). The impact of IT on supply chain agility and firm performance: An empirical investigation. International Journal of Information Management, 33(6), 909-916.

Dhar, S. (2012). From outsourcing to Cloud computing: evolution of IT services. Management Research Review, 35(8), 664-675.

Dubey, R., Gunasekaran, A., \& Childe, S. J. (2018). Big data analytics capability in supply chain agility: the moderating effect of organizational flexibility. Management Decision.

Dubey, R., Gunasekaran, A., Childe, S. J., Fosso Wamba, S., Roubaud, D., \& Forupon, C. (2019). Empirical Investigation of Data Analytics Capability and Organizational Flexibility as Complements to Supply Chain Resilience.

Durowoju, O., Chan, H. K. \& Wang, X. (2011) "The impact of security and scalability of cloud service on supply chain performance". Journal of Electronic Commerce Research, 12 (4): 243256. 
Dwivedi, Y. K., \& Mustafee, N. (2010). It's unwritten in the Cloud: the technology enablers for realising the promise of Cloud Computing. Journal of Enterprise Information Management, 23(6), 673-679.

Eisenhardt, K. M. (1989). Building theories from case study research. Academy of Management Review, Vol. 14, No. 4, pp. 532-550.

El Kadiri, S., Grabot, B., Thoben, K. D., Hribernik, K., Emmanouilidis, C., Von Cieminski, G., and Kiritsis, D. (2016). "Current trends on ICT technologies for enterprise information systems". Computers in Industry, 79, 14-33.

El-Gazzar, R. F. (2014), “A literature review on cloud computing adoption issues in enterprises”, In International Working Conference on Transfer and Diffusion of IT, Springer Berlin Heidelberg, pp. 214-242.

Fayoumi, A., (2016). Ecosystem-inspired enterprise modelling framework for collaborative and networked manufacturing systems. Computers in Industry, 80, pp.54-68.

Fox, R. (2009), "Library in the clouds", OCLC Systems \& Services, Vol. 25, No. 3, pp.156-161.

Garrison, G., Kim, S. and Wakefield, R.L. (2012), "Success factors for deploying cloud computing", Communications of the ACM, Vol. 55, No. 9, pp. 62-68.

Garrison, G., Wakefield, R. L., \& Kim, S. (2015). The effects of IT capabilities and delivery model on cloud computing success and firm performance for cloud supported processes and operations. International Journal of Information Management, 35(4), 377-393.

Gartner (2013) "Hunting and harvesting in a digital world: the 2013 CIO Agenda", Stamford.

Gonul Kochan, C., Nowicki, D. R., Sauser, B., \& Randall, W. S. (2018). Impact of cloud-based information sharing on hospital supply chain performance: A system dynamics framework. International Journal of Production Economics, 195, 168-185. doi:10.1016/j.ijpe.2017.10.008

Grant, D., \& Yeo, B. (2018). A global perspective on tech investment, financing, and ICT on manufacturing and service industry performance. International Journal of Information Management, 43, 130-145.

Handfield, R. B., and Bechtel, C. (2002), "The role of trust and relationship structure in improving supply chain responsiveness", Industrial marketing management, Vol. 31, No. 4, pp. 367-382

Helo, P., and Hao, Y. (2017), "Cloud manufacturing system for sheet metal processing”, Production Planning \& Control, Vol. 28, No. 6-8, pp. 524-537.

Helo, P., Suorsa, M., Hao, Y. and Anussornnitisarn, P. (2014), "Toward a cloud-based manufacturing execution system for distributed manufacturing", Computers in Industry, Vol. 65, No. 4, pp. 646-656.

Hogan, M., Liu, F., Sokol, A., and Tong, J. (2011). "NIST cloud computing standards roadmap". NIST Special Publication, 35.

Holweg, M. (2005), "The three dimensions of responsiveness". International Journal of Operations \& Production Management, Vol. 25, No. 7, pp. 603-622.

Hsu, P. F., Ray, S., \& Li-Hsieh, Y. Y. (2014). Examining cloud computing adoption intention, pricing mechanism, and deployment model. International Journal of Information Management, 34(4), 474-488. 
Hsu, P. F., Ray, S., \& Li-Hsieh, Y. Y. (2014). Examining cloud computing adoption intention, pricing mechanism, and deployment model. International Journal of Information Management, 34(4), 474-488.

Jede, A., \& Teuteberg, F. (2016), "Towards cloud-based supply chain processes: Designing a reference model and elements of a research agenda". The International Journal of Logistics Management, Vol. 27, No. 2, pp. 438-462.

Jones, D. and Schramm, T. (2011), "Six questions to ask about cloud computing". Supply Chain Management Review, Vol. 15, No. 3, pp. 11-17

Ketokivi, M., \& Choi, T. (2014), "Renaissance of case research as a scientific method", Journal of Operations Management, Vol. 32, No. 5, pp.232-240.

Kim, M., Suresh, N. C., and Kocabasoglu-Hillmer, C. (2013), "An impact of manufacturing flexibility and technological dimensions of manufacturing strategy on improving supply chain responsiveness: Business environment perspective". International Journal of Production Research, Vol. 51, No. 18, pp. 5597-5611.

Kiss, T., Dagdeviren, H., Taylor, S. J., Anagnostou, A., \& Fantini, N. (2015), "Business models for cloud computing: experiences from developing Modeling \& Simulation as a Service applications in industry". Proceedings of the Winter Simulation Conference, IEEE, pp. 26562667

Kumar, R., Kumar, R., Kumar Singh, R., \& Kumar Singh, R. (2017), "Coordination and responsiveness issues in SME supply chains: a review". Benchmarking: An International Journal, Vo. 24, No. 3, 635-650.

Lal, P., \& Bharadwaj, S. S. (2016), "Understanding the impact of cloud-based services adoption on organizational flexibility: An exploratory study". Journal of Enterprise Information Management, Vol. 29, No. 4, pp. 566-588.

Lee, D., \& Park, J. (2010), "RFID-enabled Supply chain traceability: existing methods, applications and challenges", INTECH Open Access Publisher.

Lian, J. W., Yen, D. C., \& Wang, Y. T. (2014). An exploratory study to understand the critical factors affecting the decision to adopt cloud computing in Taiwan hospital. International Journal of Information Management, 34(1), 28-36.

Mahmood, Z., and Hill, R. (Eds.). (2011). "Cloud Computing for enterprise architectures". Springer Science \& Business Media.

Manuel Maqueira, J., Moyano-Fuentes, J., \& Bruque, S. (2018), "Drivers and consequences of an innovative technology assimilation in the supply chain: cloud computing and supply chain integration". International Journal of Production Research, 1-21. https://doi.org/10.1080/00207543.2018.1530473.

Maréchaux, J.-L. (2006), "Combining service-oriented architecture and event-driven architecture using an enterprise service bus", IBM Developer Works, pp. 1269-1275.

Marston, S., Li, Z., Bandyopadhyay, S., Zhang, J. and Ghalsasi, A. (2011), "Cloud computing The business perspective", Decision Support Systems, Vol. 51, No. 1, pp. 176-189.

Mell, P. and T. Grance. (2011), "The NIST Definition of Cloud Computing”, [Accessed May 28, 2017]. http://csrc.nist.gov/publications/nistpubs/800-145/SP800-145.pdf 
Menge, F. (2007) "Enterprise service bus." Free and open source software conference. Vol. 2.

Mezgár, I., and Rauschecker, U. (2014) "The challenge of networked enterprises for cloud computing interoperability." Computers in Industry 65 (4): 657-674.

Ngai, E. W. T. and Gunasekaran, A. (2009), "RFID Adoption: Issues and Challenges". International Journal of Enterprise Information Systems, Vol.5, No. 1, pp. 1-8.

NIST. (2013), "NIST Cloud Computing Standards Roadmap", [Accessed May 28, 2017. http://www.nist.gov/itl/cloud/upload/NIST SP-500291 Version2 2013 June18 FINAL.pdf]

Poirier, C. C. (2003), "The networked supply chain: applying breakthrough BPM technology to meet relentless customer demands", J. Ross Publishing.

Qrunfleh, S., \& Tarafdar, M. (2014). Supply chain information systems strategy: Impacts on supply chain performance and firm performance. International Journal of Production Economics, Vol. 147, pp. 340-350.

Reichhart, A. and Holweg, M. (2007), "Creating the customer-responsive supply chain: a reconciliation of concepts". International Journal of Operations \& Production Management, Vo. 27, No. 11, pp. 1144-1172.

Sambamurthy, V., Bharadwaj, A. and Grover, V. (2003), "Shaping agility through digital options: Reconceptualizing the role of information technology in contemporary firms", MIS quarterly, pp. 237-263.

Schmidt, M. T., Hutchison, B., Lambros, P. and Phippen, R. (2005), "The Enterprise Service Bus: Making service-oriented architecture real", IBM Systems Journal, Vol. 44, No.4, pp. 781-797.

Schneider, S. and Sunyaev, A. (2016), "Determinant Factors of Cloud-Sourcing Decisions: Reflecting on the IT Outsourcing Literature in the Era of Cloud Computing", Journal of Information Technology, Vol. 31, No. 1, pp. 1-31.

Schniederjans, D. G., Schniederjans, D. G., Ozpolat, K., Ozpolat, K., Chen, Y., \& Chen, Y. (2016), "Humanitarian supply chain use of cloud computing", Supply Chain Management: An International Journal, Vo. 21, No. 5, pp. 569-588.

Senyo, P. K., Addae, E., \& Boateng, R. (2018). Cloud computing research: A review of research themes, frameworks, methods and future research directions. International Journal of Information Management, 38(1), 128-139.

Shamsuzzoha, A., Toscano, C., Carneiro, L. M., Kumar, V., \& Helo, P. (2016), "ICT-based solution approach for collaborative delivery of customised products". Production Planning \& Control, Vo. 27, No. 4, pp. 280-298.

Sharif, A. M. (2010), "It's written in the cloud: the hype and promise of cloud computing", Journal of Enterprise Information Management, Vol. 23, No. 2, pp. 131-134.

Singh, R. K. (2015), "Modelling of critical factors for responsiveness in supply chain", Journal of Manufacturing Technology Management, Vol. 26, No.6, pp. 868-888.

Sultan, N. (2013). Knowledge management in the age of cloud computing and Web 2.0: Experiencing the power of disruptive innovations. International journal of information management, 33(1), 160-165. 
Sultan, N. (2014). Making use of cloud computing for healthcare provision: Opportunities and challenges. International Journal of Information Management, 34(2), 177-184.

Sultan, N. A. (2011). "Reaching for the cloud: How SMEs can manage". International journal of information management, 31(3), 272-278.

Supply Chain Council (2012), "Supply Chain Operations Reference (SCOR) Model Overview”. [Last access date: 25 September 2017] http://supply-chain.org/f/Web-Scor-Overview.pdf

Swafford, P. M., Ghosh, S., \& Murthy, N. (2008), "Achieving supply chain agility through IT integration and flexibility". International Journal of Production Economics, Vol. 116, No. 2, pp. 288-297.

Tiwari, M. K., Mahanty, B., Sarmah, S. P., \& Jenamani, M. (2012), "Modeling of responsive supply chain", CRC Press.

Van Hoek, R., Harrison, A., and Christopher, M. (2001). Measuring agile capabilities in the supply chain. International Journal of Operations \& Production Management, 21(1/2), 126-148.

Vazquez-Martinez, G. A., Gonzalez-Compean, J. L., Sosa-Sosa, V. J., Morales-Sandoval, M., \& Perez, J. C. (2018). CloudChain: A novel distribution model for digital products based on supply chain principles. International Journal of Information Management, 39, 90-103.

Venters, W., and Whitley, E. A. (2012). A critical review of cloud computing: researching desires and realities. Journal of Information Technology, 27(3), 179-197.

Verwijmeren, M. (2004), "Software component architecture in supply chain management", Computers in industry, Vol. 53, No. 2, pp. 165-178.

Wald, H. (2010), "Cloud Computing for the Federal Community". Cloud Computing: Silver Lining or Storm Ahead, Vol. 13, No. 2, pp. 10-15.

Walterbusch, M., Fietz, A., \& Teuteberg, F. (2017), "Missing cloud security awareness: investigating risk exposure in shadow IT", Journal of Enterprise Information Management, Vol. 30, No. 4, pp.644-665.

Wang, L., Banjan, R., Chen, J. and Benatallah, B. (2012) Cloud computing: methodology, systems, and applications. Boca Raton, FL: CRC Press

Williams, M. D., Rana, N. P., \& Dwivedi, Y. K. (2015). The unified theory of acceptance and use of technology (UTAUT): a literature review. Journal of Enterprise Information Management, 28(3), 443-488.

Wu, D., Greer, M.J., Rosen, D.W. and Schaefer, D. (2013), "Cloud manufacturing: Strategic vision and state-of-the-art", Journal of Manufacturing Systems, Vol. 32, No. 4, pp. 564-579.

Wu, L., \& Chiu, M. L. (2018). Examining supply chain collaboration with determinants and performance impact: Social capital, justice, and technology use perspectives. International Journal of Information Management, 39, 5-19.

Wu, Y., Cegielski, C. G., Hazen, B. T., \& Hall, D. J. (2013), “Cloud computing in support of supply chain information system infrastructure: understanding when to go to the cloud2, Journal of Supply Chain Management, No. 49, Vol. 3, pp. 25-41.

$\mathrm{Xu}, \mathrm{X}$. (2012), "From cloud computing to cloud manufacturing", Robotics and ComputerIntegrated Manufacturing, Vol. 28, No. 1, pp. 75-86. 
Yang, J. J., Li, J., Mulder, J., Wang, Y., Chen, S., Wu, H., \& Pan, H. (2015), "Emerging information technologies for enhanced healthcare", Computers in Industry, 69, 3-11.

Yeo, C. S., Venugopal, S., Chu, X., \& Buyya R. (2009), “Autonomic metered pricing for a utility computing service”, Future Generation Computer Systems, Vol. 26, No. 8, pp.1368-1380.

Zhang, L., Y. Luo, F. Tao, B. H. Li, L. Ren, X. Zhang, and Y. Liu. (2014). "Cloud Manufacturing: A New Manufacturing Paradigm.” Enterprise Information Systems, Vol. 8, No.2, pp. 167-187.

Zhang, Q., Cheng, L. \& Boutaba, R. (2010), "Cloud computing: state-of-the-art and research challenges". Journal of Internet Services and Applications, Vol. 1, No. 1, pp. 7-18. 